\title{
Randomised controlled trial of physiological and ventricular pacing
}

\author{
E JOHN PERRINS, CHRISTOPHER A MORLEY, SIEW LU CHAN, RICHARD SUTTON \\ From the Department of Cardiology, Westminster Hospital, London
}

SUMMARY Thirteen patients have completed a randomised double blind cross over study to compare the effects of chronic ventricular and atrial synchronous pacing on exercise capacity and symptoms. Maximal symptom limited exercise was significantly increased after one month of atrial synchronous pacing compared with ventricular pacing. Symptomatic assessment (by diary card and monthly symptom scores) of "shortness of breath", "palpitation", and "general well-being" was significantly improved during the physiological pacing mode. Atrial synchronous pacing has been shown to be superior to ventricular pacing.

Cardiac pacing is a safe and established treatment for patients with symptomatic bradycardia caused by atrioventricular block. Until recently, however, this treatment has been restricted to ventricular demand pacing at a constant rate. Recent advances in lead design allow the reliable implantation of endocardial atrial leads, ${ }^{1-3}$ and several pacemakers are now available which can restore the normal activation sequence of atrial contraction followed by ventricular systole and which, furthermore, can follow physiological increases in heart rate during exercise. The indications and applications of these pacemakers have recently been reviewed. ${ }^{4}$

There remains controversy as to whether these more complex and, at present, more expensive pacemakers confer any real advantages to the patient. Pacemakers are now available which are programmable to either ventricular inhibited (VVI) pacing or a physiological mode (atrial sychronous ventricular inhibited, VDD or universal, DDD). ${ }^{5}$ It has been possible therefore using these pacemakers to compare these two modes of pacing in terms of both exercise performance and patient symptoms in a double blind trial.

\section{Patients and methods}

PATIENT SELECTION

Patients in whom a mode programmable VDD pacemaker had been implanted for at least three months were considered suitable candidates for the

Accepted for publication 15 February 1983 trial. At the time of the study the exclusion criteria for implantation of a VDD pacemaker were: severe physical disability (for example arthritis or stroke), the coincidence of another disease with a short prognosis, chronic atrial fibrillation, the presence of dominant sinus rhythm with rare episodes of bradycardia, carotid sinus syndrome, retrograde atrioventricular conduction, isolated sick sinus syndrome, and very thin patients. In the four years before the trial 350 patients had been paced, of whom 42 had received VDD or VAT (ventricular paced atrial sensed) implants. Of these, only 16 were mode programmable (VDDM). One patient refused and two patients had intermittent 2:1 block at the time of the study, leaving 13 patients. Their clinical details are shown in Table 1. All patients had symptomatic Mobitz II or complete atrioventricular block and normal (nine patients) or borderline (two patients) sinus node disease assessed by prepacing electrophysiological studies. Their mean age was 65 years (range 32 to 87). None of the patients had been found to conduct during exercise before entry. The patients had had their pacemaker implanted in VDD mode for a mean of 11 months (range three to 27) before entry into the trial to ensure that they were haemodynamically stable at entry.

\section{TRIAL DESIGN}

The trial was designed as a within patient double blind prospective study of symptoms and exercise tolerance between two pacing modalities, VVI and VDD. The design is shown in Fig. 1. There were three consecutive one month periods during which patients were asked to keep diary cards of their symptoms and a maximal stress test was performed at the 
Table 1 Patient data

\begin{tabular}{|c|c|c|c|c|c|c|}
\hline Case No. & Age, sex & Pacemaker & Months since implant & Prepacing symptoms & Prepacing electrocardiogram & Aetiology \\
\hline $\begin{array}{r}1 \\
2 \\
3 \\
4 \\
5 \\
6 \\
7 \\
8 \\
9 \\
10 \\
11 \\
12 \\
13\end{array}$ & $\begin{array}{l}64 M \\
67 \mathrm{~F} \\
51 \mathrm{M} \\
63 \mathrm{M} \\
51 \mathrm{~F} \\
87 \mathrm{M} \\
68 \mathrm{M} \\
66 \mathrm{~F} \\
84 \mathrm{M} \\
73 \mathrm{M} \\
74 \mathrm{M} \\
32 \mathrm{~F} \\
66 \mathrm{M}\end{array}$ & $\begin{array}{l}\text { VDDM } \\
\text { VDDM } \\
\text { VDDM } \\
\text { VDDM } \\
\text { VDDM } \\
\text { VDDM } \\
\text { VDDM } \\
\text { VDDM } \\
\text { VDDM } \\
\text { VDDM } \\
\text { VDDM } \\
\text { DDDM } \\
\text { DDDM }\end{array}$ & $\begin{array}{r}16 \\
16 \\
13 \\
27 \\
12 \\
27 \\
14 \\
8 \\
5 \\
3 \\
6 \\
3 \\
3\end{array}$ & $\begin{array}{l}\text { Syncope } \\
\text { Syncope } \\
\text { Syncope } \\
\text { Syncope } \\
\text { Syncope, dyspnoea } \\
\text { Syncope, dyspnoea } \\
\text { Dyspnoea } \\
\text { Syncope } \\
\text { Syncope } \\
\text { Syncope } \\
\text { Syncope, dyspnoea } \\
\text { Dyspnoea } \\
\text { Syncope }\end{array}$ & $\begin{array}{l}\text { Mobitz II 2:1 } \\
\text { CHB } \\
\text { Mobitz II 2:1 } \\
\text { Mobitz II 2:1 } \\
\text { CHB } \\
\text { CHB } \\
\text { Mobitz II 2:1 } \\
\text { Mobitz II 2:1 } \\
\text { CHB } \\
\text { Mobitz II 2:1 } \\
\text { CHB } \\
\text { CHB } \\
\text { Mobitz II 2:1 }\end{array}$ & $\begin{array}{l}\text { Fibrosis } \\
\text { Fibrosis } \\
\text { Fibrosis } \\
\text { COCM } \\
\text { After CABG } \\
\text { Fibrosis } \\
\text { Fibrosis } \\
\text { Fibrosis } \\
\text { Fibrosis } \\
\text { Ischaemia } \\
\text { Fibrosis } \\
\text { Congenital } \\
\text { Fibrosis }\end{array}$ \\
\hline
\end{tabular}

$\star$ Fibrosis indicates that the presumed aetiology was idiopathic fibrosis of the ventricular conduction system.

CHB, congestive heart block; COCM obstructive cardiomyopathy; CABG, coronary artery bypass graft.

end of each study period. All patients had been in the VDD pacing mode for at least three months before the study.

The first month was a run-in period to familiarise the patients with the symptom cards and the stress tests. During this first month the pacemaker mode was randomly programmed to either VVI or VDD mode but data collected for this first period were not subsequently analysed. The sequence of modes for each patient is shown in Table 2 . For the second and third months the choice of mode was random between VVI followed by VDD or VDD followed by VVI. The mode was programmed randomly in the run in

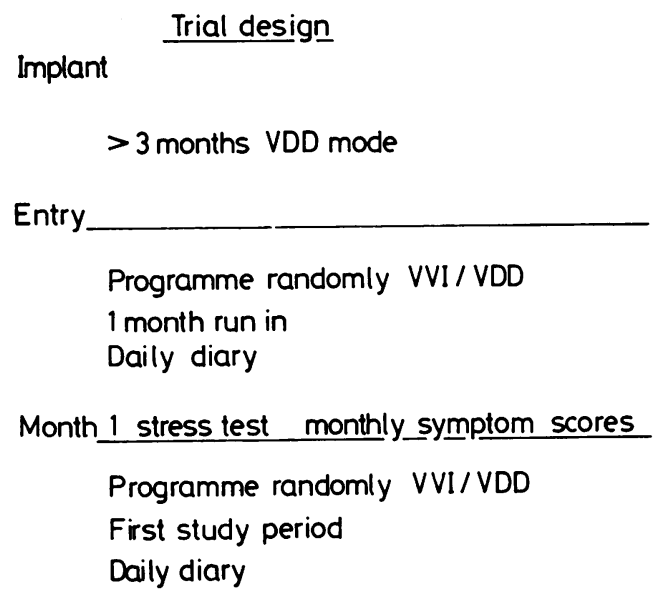

Month 2 stress test monthly symptom scores

Programme to other mode

Second study period

Daily diary

Month 3 stress test monthly symptom scores

Fig. 1 Trial design. period to ensure that all possible combinations of change in pacing mode were possible (the sequence VVI-VVI-VDD and VVI-VDD-VVI would not have occurred otherwise).

At entry to the trial and at the end of each study month the patients underwent a symptom limited maximum exercise stress test (bicycle ergometer) and total exercise capacity and maximum atrial rate were recorded. These tests were performed at the same time of day for each patient. In the VVI mode ventricular rate was set at $70 \mathrm{bpm}$; in the physiological mode the back-up rate was $50 \mathrm{bpm}$, the atrioventricular delay $150 \mathrm{~ms}$, and the upper synchronous rate $150 \mathrm{bpm}$. The programmed mode was blind to the patient and observer.

The patients kept a daily diary card of their symptoms and were asked to record the number of attacks of chest pain, dizziness; palpitation, and syncope experienced each day. At the end of each month the patients were asked in addition to give a subjective score to the following symptoms in comparison with the previous month: chest pain, dizziness, shortness of breath, palpitation, and general well-being. The scores were 1- much worse, 2- a little worse, 3- no change, 4 a little improved, 5- much improved.

Table 2 Sequence of pacing modes

\begin{tabular}{llll}
\hline Case No. & Period 1 & Period 2 & Period 3 \\
\hline 1 & VDD & VDD & VVI \\
2 & VDD & VVI & VDD \\
3 & VVI & VDD & VVI \\
4 & VDD & VVI & VDD \\
5 & VVI & VVI & VDD \\
6 & VVI & VDD & VVI \\
7 & VVI & VDD & VVI \\
8 & VDD & VVI & VDD \\
9 & VDD & VVI & VDD \\
10 & VDD & VDD & VVI \\
11 & VVI & VVI & VDD \\
12 & VDD & VDD & VVI \\
13 & VDD & VDD & VVI \\
\hline
\end{tabular}




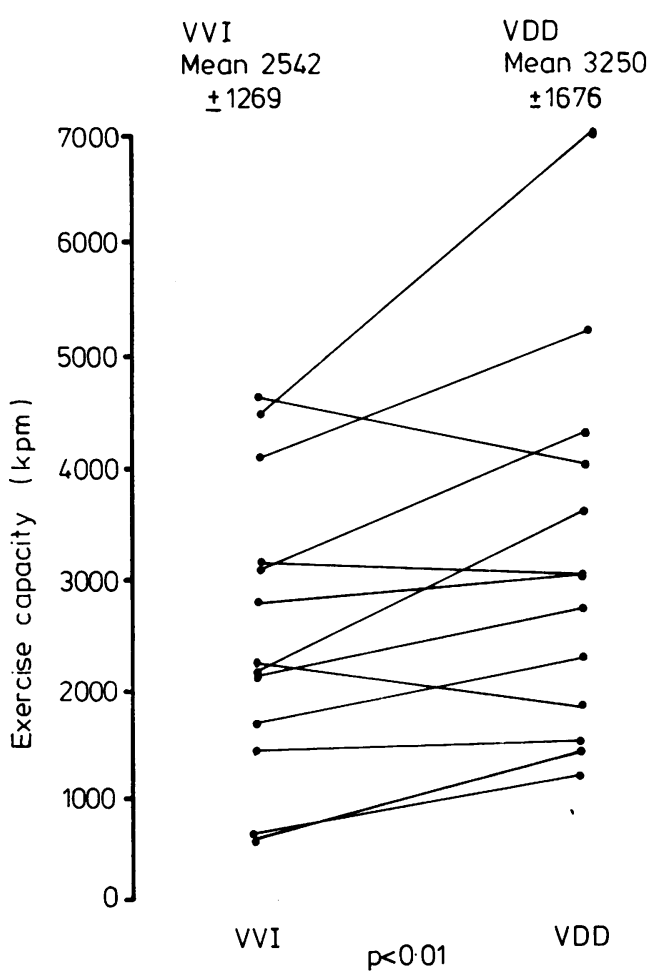

Fig. 2 Maximal effort tolerance after chronic ventricular (VVI) and physiological pacing (VDD).

Only symptoms expenenced during the second and third months were subsequently compared and analysed.

Analysis of the record card data was blind to the observer. The patients were blind to the pacing mode. In view of the necessity to monitor the electrocardiogram during the exercise test this part of the study could not be blind to the observer. All stress tests and pacemaker programming were therefore performed by one of us (SLC) who was not subsequently involved in the analysis. In view of the ease of determining which pacing mode the patients were in (by, for example, feeling the pulse) the patients were deliberately not interviewed or examined during the study period.

\section{STATISTICAL METHODS}

Comparisons of the maximal exercise tests were made by a paired Student's $t$ test. The comparisons for symptoms were expressed as number of attacks a week for each month and compared by Wilcoxon's ranked pairs test. The latter test was also used to compare the symptom scores. A p value of $<0.05$ was regarded as significant.

\section{Results}

Exercise tolerance was significantly greater during the physiological pacing mode (Fig. 2 and Table 3). The mean effort tolerance was $3250 \pm 1676 \mathrm{kpm}$ during VDD pacing and $2542 \pm 1269 \mathrm{kpm}$ during VVI pacing, an improvement of $27 \%(p<0.01)$. None of the patients developed retrograde atrioventricular conduction during VVI pacing. There were no significant differences between the maximal atrial rates achieved during the two pacing modes. Four patients had little change in maximum effort tolerance. Three of these were found to have developed intermittent antero-

Table 3 Monthly symptom scores for shortness of breath and general well-being: total workload achieved in VVI and VDD modes together with maximum atrial rates

\begin{tabular}{|c|c|c|c|c|c|c|c|c|}
\hline \multirow[t]{2}{*}{$\begin{array}{l}\text { Case } \\
\text { No. }\end{array}$} & \multicolumn{2}{|c|}{ Effort tolerance $(\mathrm{kpm})$} & \multicolumn{2}{|c|}{ Maximum atrial rate (bpm) } & \multicolumn{2}{|c|}{$\begin{array}{l}\text { Symptom score } \\
\text { "shortness of breath" }\end{array}$} & \multicolumn{2}{|c|}{$\begin{array}{l}\text { Symptom score } \\
\text { "general well-being" }\end{array}$} \\
\hline & $V V I$ & $V D D$ & $V V I$ & $V D D$ & $V V I$ & $V D D$ & $V V I$ & $V D D$ \\
\hline $\begin{array}{c}1 \\
2 \\
3 \\
4 \\
5 \\
6 \\
7 \\
8 \\
9 \\
10 \\
11 \\
12 \\
13 \\
\text { Mean }\end{array}$ & $\begin{array}{c}3150 \\
1450 \\
4500 \\
4100 \\
650 \\
2200 \\
4300 \\
700 \\
1700 \\
2250 \\
2150 \\
2800 \\
3100 \\
2542 \star \star \\
\pm 1269\end{array}$ & $\begin{array}{l}3100 \\
1600 \\
7100 \\
5300 \\
1500 \\
3700 \\
4100 \\
1300 \\
2350 \\
1900 \\
2800 \\
3100 \\
4400 \\
3250 \star \star \\
\pm 1676\end{array}$ & $\begin{array}{l}148 \\
100 \\
140 \\
135 \\
130 \\
145 \\
120 \\
145 \\
125 \\
82 \\
140 \\
145 \\
110 \\
128.1 \dagger \\
\pm 20.2\end{array}$ & $\begin{array}{l}150 \\
120 \\
150 \\
145 \\
140 \\
145 \\
130 \\
140 \\
125 \\
85 \\
145 \\
130 \\
150 \\
135 \dagger \\
\pm 18.0\end{array}$ & $\begin{array}{l}1 \\
3 \\
1 \\
3 \\
1 \\
2 \\
1 \\
3 \\
3 \\
3 \\
2 \\
2 \\
1 \\
2.0^{\star \star} \\
\pm 0.91\end{array}$ & $\begin{array}{l}3 \\
3 \\
4 \\
3 \\
5 \\
5 \\
3 \\
3 \\
3 \\
3 \\
4 \\
3 \\
3 \\
3.45 \star \star \\
\pm 0.80\end{array}$ & $\begin{array}{l}2 \\
2 \\
1 \\
2 \\
1 \\
2 \\
2 \\
3 \\
1 \\
2 \\
2 \\
2 \\
1 \\
1.72 \star \star \\
\pm 0.60\end{array}$ & $\begin{array}{l}3 \\
4 \\
4 \\
2 \\
5 \\
4 \\
4 \\
3 \\
4 \\
3 \\
3 \\
4 \\
3 \\
3.54 \\
\pm 0.80\end{array}$ \\
\hline
\end{tabular}

$\star \star p<0.01$.

tp $=$ NS. 


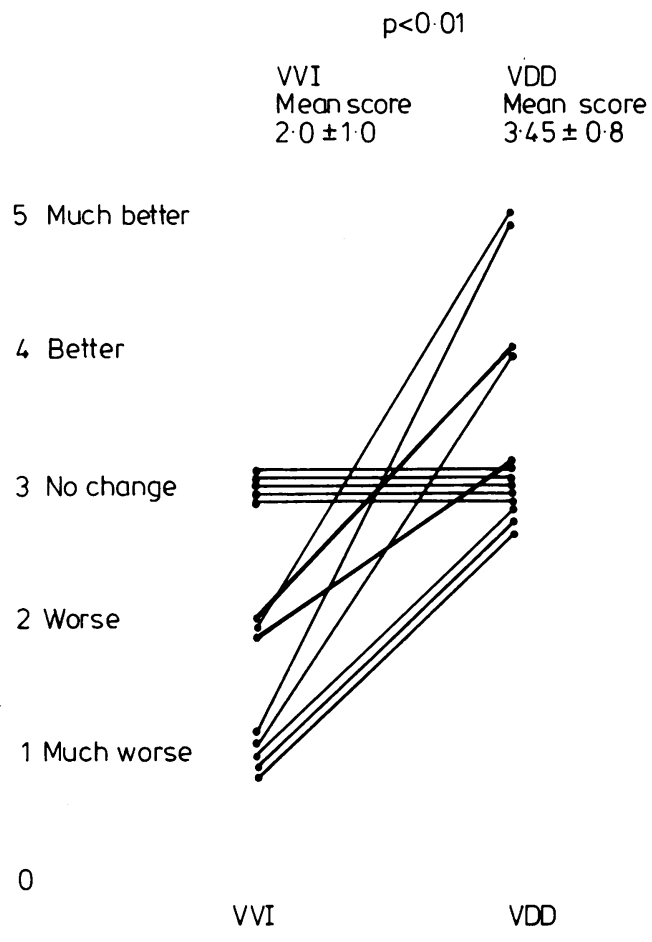

Fig. 3 Symptom scores for "shortness of breath".

grade conduction during the VVI stress test and had achieved similar ventricular rates during both modes. The fourth patient developed angina soon after the start of the study and was given beta blockers and was unable to achieve an atrial rate during exercise of greater than $85 \mathrm{bpm}$ in either mode. The statistical analysis was on an "intention to treat basis", that is these patients were not excluded. The subjective assessment of "shortness of breath" was also improved during the physiological mode, with a mean symptom score of $3.45 \pm 0.8$ during VDD and $2.0 \pm 0.91$ during VVI $(p<0.01$, Table 3, Fig. 3). The comparisons of symptoms during VVI and physiological pacing are shown in Tables 4 and 5 . It can be seen that no patient experienced syncope during the

Table 4 Weekly attack rates and monthly symptom scores of symptoms-dizziness, palpitation, and chest pain

\begin{tabular}{|c|c|c|c|c|c|c|}
\hline \multirow[t]{2}{*}{ Symptom } & \multicolumn{3}{|c|}{ Attacks per week } & \multicolumn{3}{|c|}{ Mean symptom score } \\
\hline & $\overline{V V I}$ & $V D D / D D D$ & $P$ & $V V I$ & $V D D / D D D$ & $P$ \\
\hline $\begin{array}{l}\text { Syncope } \\
\text { Dizziness }\end{array}$ & $\begin{array}{c}0 \\
2.49 \\
+4.7\end{array}$ & $\begin{array}{l}0 \\
1.45 \\
+2.67\end{array}$ & $\begin{array}{l}\text { NS } \\
\text { NS }\end{array}$ & $\begin{array}{c}3 \\
2.3 \\
\pm 0.91\end{array}$ & $\begin{array}{l}3 \\
3.5 \\
\pm 0.70\end{array}$ & $\begin{array}{l}\text { NS } \\
<0.02\end{array}$ \\
\hline Palpitation & $\begin{array}{r}1.76 \\
+2.86\end{array}$ & $\begin{array}{r}0.35 \\
\pm 1.22\end{array}$ & $<0.05$ & $\begin{array}{c}2.6 \\
\pm 0.69\end{array}$ & $\begin{array}{c}3.3 \\
\pm 0.67\end{array}$ & $<0.05$ \\
\hline Chest pain & $\begin{array}{r}1.08 \\
\pm 1.30\end{array}$ & $\begin{array}{r}1.16 \\
\pm 2.01\end{array}$ & NS & $\begin{array}{r}2.9 \\
\pm 0.31\end{array}$ & $\begin{array}{r}3.1 \\
\pm 1.1\end{array}$ & NS \\
\hline
\end{tabular}

Table 5 Weekly attack rates for individual patients

\begin{tabular}{|c|c|c|c|c|c|c|}
\hline \multirow[t]{2}{*}{$\begin{array}{l}\text { Case } \\
\text { No. }\end{array}$} & \multicolumn{2}{|c|}{$\begin{array}{l}\text { Palpitation } \\
\text { (attacks/wk) }\end{array}$} & \multicolumn{2}{|c|}{$\begin{array}{l}\text { Dizziness } \\
\text { (attacks/wk) }\end{array}$} & \multicolumn{2}{|c|}{$\begin{array}{l}\text { Chest pain } \\
\text { (attackshwk) }\end{array}$} \\
\hline & $V V I$ & $V D D$ & $V V I$ & $V D D$ & $V V I$ & $V D D$ \\
\hline $\begin{array}{c}1 \\
2 \\
3 \\
4 \\
5 \\
6 \\
7 \\
8 \\
9 \\
10 \\
11 \\
12 \\
13 \\
\text { Mean }\end{array}$ & $\begin{array}{l}0 \\
1.5 \\
8.5 \\
1.5 \\
0 \\
1 \\
3.5 \\
0 \\
0 \\
0 \\
0 \\
0 \\
7 \\
1.76 \star \\
\pm 2.86\end{array}$ & $\begin{array}{l}0 \\
0 \\
4 \\
0.5 \\
0 \\
0 \\
0 \\
0 \\
0 \\
0 \\
0 \\
0 \\
0 \\
0.35 * \\
\pm 1.22\end{array}$ & $\begin{array}{l}0 \\
9 \\
0 \\
0 \\
0 \\
1 \\
1.45 \\
0 \\
2.25 \\
2.75 \\
0 \\
0 \\
16 \\
2.49+ \\
\pm 4.7\end{array}$ & $\begin{array}{l}0 \\
8 \\
3.5 \\
0 \\
0 \\
0 \\
1.17 \\
0 \\
6 \\
0 \\
0 \\
0 \\
0.25 \\
1.45+ \\
+2.67\end{array}$ & $\begin{array}{l}0 \\
0.5 \\
4 \\
1.5 \\
0 \\
0 \\
3 \\
2.25 \\
0.91 \\
1.5 \\
0 \\
0 \\
0.5 \\
1.08 千 \\
\pm 1.30\end{array}$ & $\begin{array}{l}0 \\
0 \\
1 \\
7 \\
0 \\
0 \\
0.5 \\
1.5 \\
3.17 \\
2 \\
0 \\
0 \\
0 \\
1.16+ \\
\pm 2.01\end{array}$ \\
\hline
\end{tabular}

${ }^{\star} \mathrm{p}<0.05$.

$\mathrm{tp}=\mathrm{NS}$.

study. Dizziness was experienced more often during VVI pacing, but this only reached statistical significance for the monthly symptom score. Feelings of palpitation were also more frequent during VVI pacing and this was significant $(p<0.05)$ for both the weekly attack rate and the monthly symptom score. There were no significant differences between the two pacing modes for chest pain.

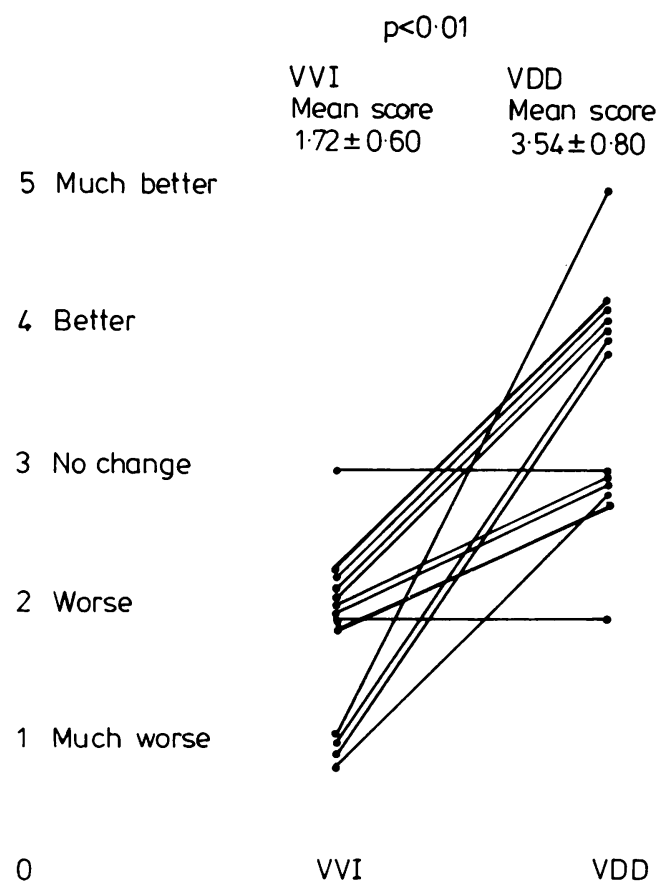

Fig. 4 Symptom scores for "general well-being". 
The patient's subjective sensation of well-being was much improved during physiological pacing (symptom scores $3.54 \pm 0.08 \mathrm{VDD}, 1.72 \pm 0.06 \mathrm{VVI}$, $\mathrm{p}<0.01$ ) (Fig. 4.)

\section{Discussion}

There are currently few published data concerning the long term clinical effects of physiological pacing in man. There have been several haemodynamic studies comparing atrioventricular sequential (DVI) and VVI pacing acutely at rest and during exercise. ${ }^{6-8}$ These authors have shown improved left ventricular haemodynamics when atrioventricular synchrony is maintained. Very few long term data are available, however. Sutton et al. ${ }^{9}$ have reported sustained improvement in exercise capacity after physiological pacing and two recent papers have shown chronic improvement in haemodynamic variables during VDD compared with VVI pacing. ${ }^{1011}$ Neither of these two studies, however, has looked at symptoms in detail nor were they randomised controlled trials. Though the theoretical symptomatic benefits of physiological pacing are often expounded, no controlled data exist.

This prospective controlled study has shown that physiological pacing increases the maximal effort tolerance of patients when compared with VVI pacing and that this improvement persists over a period of one month. This is in contrast to VVI pacing where a diminution in haemodynamic performance has been seen chronically. ${ }^{12}$ Three of the four patients with no benefit were found to have conducted intermittently during the stress test in the VVI mode. If these patients are excluded from analysis of exercise data then the $p$ value changes from $<0.01$ to $<0.001$.

Many patients with pacemakers, however, do not normally exercise to their maximum capacity and it is important therefore that subjective symptoms are improved by physiological systems. Ventricular pacing is an extremely effective treatment for preventing syncope caused by bradycardia and patients in the pacemaker clinic generally have few complaints after VVI pacing. Recent work, however, has shown that minor symptoms of dizziness and palpitation are common in VVI paced patients because of atrioventricular dissociation or retrograde atrioventricular conduction, often termed the pacemaker syndrome. An extreme form of this is when syncope occurs usually at the onset of ventricular pacing. ${ }^{13}$ Some groups of patients are exceptionally susceptible to this phenomenon, particularly patients with the hypersensitive carotid sinus syndrome. ${ }^{14}$ Similarly, patients with predominantly normal sinus rhythm may be acutely aware of the onset of ventricular pacing. This was one rationale behind the negative rate hysteresis pacemaker. ${ }^{15}$

It is of importance therefore that subjective symptoms of dizziness and palpitation were less during the physiological mode, as was the improvement in the patient's overall feelings of well-being and improved effort tolerance. This occurred despite the fact that all of the patients had predominantly paced rhythm in the VVI mode and had been shown at electrophysiological study and subsequently not to exhibit retrograde atrioventricular conduction. There was considerable individual variation in symptoms, with patients often expressing a preference for the physiological mode with respect to a particular symptom without recording any specific instances of that symptom in the daily diary.

This study was designed as a within patient double blind trial. Unfortunately it was impossible to maintain blindness to the observer during the stress test and this may have biased the results. The intelligent patient could of course determine which mode he was in by feeling his own pulse and it is impossible to know how much this influenced the results. It is interesting to note that several patients were acutely aware of the change from VVI to VDD mode. These problems could only be overcome by a large parallel group study.

This study has been carried out on a small selected group of patients and has shown clear symptomatic benefits of atrial synchronous pacing compared with ventricular inhibited pacing. Dual chambered pacing systems are, however, more complex and expensive and are not applicable to all patients. It does not seem justified to implant these systems in severely disabled patients or those with another terminal condition unless the patient has a clear symptomatic complication of VVI pacing, for example pacemaker syndrome. These patients may, however, be managed more simply by rate hysteresis VVI pacing ${ }^{16}$ or DVI pacing rather than VDD or DDD units. Permanent atrial fibrillation is a clear contraindication to any conventional atrial system; intermittent atrial fibrillation, however, may allow a DDD system to be implanted if the arrhythmia is suppressed with drugs such as amiodarone but it has not yet been our practice to do this. Retrograde atrioventricular conduction is a relative contraindication because of the possibility of pacemaker induced artificial circus movement tachycardias. This problem has recently been reviewed. ${ }^{1718}$ Retrograde conduction may be expected in about $13 \%$ of patients with complete heart block, $46 \%$ with intermittent (Mobitz II) block, and $89 \%$ of other patients with symptomatic bradycardia. ${ }^{19}$ Though artificial circus movement tachycardias may be to some extent controlled by advances in technology (for example programmable atrial refractory period) in the newer multiprogrammable DDD 
pacemakers and in some instances by drugs, ${ }^{20}$ retrograde atrioventricular conduction must be carefully assessed before implantation of a dual chamber atrial sensing system is contemplated. The physical size of these units is still a problem in some patients. At this centre only 30 to $40 \%$ of patients presenting for pacing are found to be suitable for physiological pacing.

In conclusion this study has shown that physiological pacing offers improved effort tolerance and symptomatic improvement when compared with ventricular pacing. The increase in implant complexity and cost is clearly justified in selected patients, and atrial synchronous ventricular inhibited pacemakers should be at least considered in all patients with symptomatic bradycardia caused by atrioventricular block.

\section{References}

1 Kruse IB, Rydén L, Ydse B. Clinical and electrophysiological characteristics of a transvenous atrial lead. Br Heart $\mathcal{F}$ 1979; 42: 595-602.

2 Bisping HJ, Kreuzer J, Birkenheier $H$. Three year clinical experience with a new endocardial screw-in lead with introduction protection for use in the atrium and ventricle. Pace 1980; 3: 424-35.

3 Perrins EJ, Sutton R, Kalebic B, Richards L, Morley C, Terpstra $B$. Modern atrial and ventricular leads for permanent cardiac pacing. Br Heart $\mathcal{f}$ 1981; 46: 196-201.

4 Sutton R, Perrins EJ, Citron P. Physiological cardiac pacing. A review. Pace 1980; 3: 207-19.

5 Parsonnet V, Furman S, Smyth NPD, et al. A revised code for pacemaker identification. Report of pacemaker study group. Circulation 1981; 64 (No. 1): A60-2.

6 Berkowits BV, Castellanos A, Lemberg L. Bifocal demand pacing. Circulation 1969; 40 (suppl III): 44-9.

7 Karlöf I. Haemodynamic effect of atrial triggered versus fixed rate ventricular pacing at rest and during exercise in complete heart block. Acta Med Scand 1975; 197: 195206.

8 Kruse LB, Rydén L. Comparison of physical work capacity and systolic time intervals with ventricular inhibited and atrial synchronous ventricular inhibited pacing. $\mathrm{Br}$ Heart $\mathcal{F}$ 1981; 46: 129-36.

9 Sutton R, Perrins EJ, Kalebic B, Richards LR. Physiological cardiac pacing in atrioventricular block: acute and long term studies [Abstract]. Pace 1980; 3: 388.

10 Kruse I, Arnman K, Conradson TB, Rydén L. A comparison of the acute and long term hemodynamic effects of ventricular inhibited and atrial synchronous ventricular inhibited pacing. Circulation 1981; 65: 846-55.

11 Kappenberger L, Gloor HO, Babotai I, Steinbrunn W, Turina M. Haemodynamic effects of atrial synchronisation in acute and long-term ventricular pacing. Pace 1980; 5: 639-45.

12 Nager F, Bühlmann A, Schaub F. Klinische und hämodynamische Befunde beim totalen AV-Block nach Implantation elektrischer Schrittmacher. Helv Med Acta 1967; 33: 240-76.

13 Alicandri C, Fouad FM, Tarazi RC, Castle L, Morant V. Three cases of hypotension and syncope with ventricular pacing. Possible role of atrial reflexes. Am $\mathcal{f}$ Cardiol 1978; 42: 137-42.

14 Morley C, Perrins EJ, Chan SL, Sutton R. An analysis of persistent symptoms in patients paced for the hypersensitive carotid sinus syncope [Abstract]. Br Heart $\mathcal{F}$ 1982; 47: 203.

15 Preston TA, Preston AW Jr. The automatic rate adjustment pacernaker and possibilities of rate hysteresis. Pace 1978; 1: 178-85.

16 Azulay A, Vagnini FJ, Saha CK. Permanent prophylactic ventricular demand pacing with VVI extended negative rate hysteresis. In: Meere C, ed. Proceedings of the VIth World Symposium on cardiac pacing. Montreal: Pacesymp, 1978: chapter 16.5.

17 Bathen J, Gundersen T, Forfang K. Tachycardias related to atrial synchronous ventricular pacing. Pace 1982: 5: 471-5.

18 Den Dulk K, Lindemans F, Bàr FW, Wellens HJJ. Pacemaker related tachycardias. Pace 1982; 5: 476-85.

19 Morley C, Sutton R, Perrins EJ, Chan SL. Importance of retrograde conduction in physiological cardiac pacing [Abstract]. Pace 1981; 4: A-40.

20 Hellestrand KJ, Bexton RS, Nathan AW, Spurrell RAJ, Camm AJ. Acute electrophysiological effects of flecainide acetate on cardiac conduction and refractoriness in man. Br Heart f 1982; 48: 140-8.

Requests for reprints to Dr E J Perrins, Department of Cardiology, Westminster Hospital, Horseferry Road, London SWIP 2AP. 
13 Aronstam EM, Strader LD, Geiger JP, Gomez AC. Traumatic left ventricular aneurysms. $\mathcal{F}$ Thorac Cardiovasc Surg 1970; 59: 239-42.

14 Watson JH, Bartholomae WM. Cardiac injury due to non-penetrating chest trauma. Ann Intern Med 1960; 52: 871-80.

15 Fox KM, Rowland E, Krikler DM, Bentall HH, Good- win JF. Electrophysiological manifestations of nonpenetrating cardiac trauma. Br Heart $\mathcal{F} 1980 ; 43$ : 458-62.

Requests for reprints to Dr David L Stone, Regional Cardiac Unit, Papworth Hospital, Papworth Everard, Cambridge CB3 8RE.

\section{Notice}

\section{British Cardiac Society}

The Autumn Meeting will be held at Wembley on 21 and 22 November 1983, and the closing date for abstracts was 26 July 1983.

The Annual General Meeting for 1984 will take place in Leicester on 11 and 12 April 1984, and the closing date for receipt of abstracts will be 3 January 1984.

The Autumn Meeting in 1984 will be held on 3 and 4 December 1984, and the closing date for receipt of abstracts will be 15 August 1984 .

\section{Corrigendum}

We regret the following errors in the paper in the August issue by Dr E J Perrins and others on randomised controlled trial of physiological and ventricular pacing (p 112). In the footnote to Table $1 \mathrm{CHB}$ should read complete heart block and COCM should read congestive cardiomyopathy. 